Çukurova Üniversitesi Mühendislik Fakültesi Dergisi, 36(3), ss. 691-700, Eylül 2021

Çukurova University Journal of the Faculty of Engineering, 36(3), pp. 691-700, September 2021

\title{
Molibden ve Vanadyum İlavesinin Fe-Cr-C Sert Dolgu Alaşımlarının Aşınma Direncine Etkisi
}

\author{
Nilay ÇÖMEZ ${ }^{*}$, Canser GÜL ${ }^{1}$, Hülya DURMUŞ ${ }^{1}$ \\ ${ }^{1}$ Manisa Celal Bayar Üniversitesi, Mühendislik Fakültesi, Metalurji ve Malzeme Mühendisliği \\ Bölümü, Manisa
}

Geliş tarihi: 18.05.2021 Kabul tarihi: 13.09.2021

$\ddot{\mathbf{O z}}$

Sert dolgu kaplamalar, pek çok mühendislik uygulamasında iş parçalarının aşınma ve korozyon direncini artırmak amacıyla kullanılan yöntemlerden biridir. Bu çalışmanın amacı, karbür yapıcı elementlerden molibden ve vanadyumun $\mathrm{Fe}-\mathrm{Cr}-\mathrm{C}$ esaslı sert dolgu alaşımlarına ilave edilerek mikroyapı ve aşınma özelliklerinde meydana gelecek değişimleri incelemektir. Her kaplama hem vanadyum hem de molibden içermektedir. Fe-Cr-C alaşımlarına \%3, \%4 oranlarında ferromolibden, \%10, \%12 oranlarında ferrovanadyum ilave edilmiştir. Kaplama içeriğinin primer $\mathrm{M}_{7} \mathrm{C}_{3}(\mathrm{M}$ : $\mathrm{Fe}, \mathrm{Cr})$ ve $\mathrm{M}_{2} \mathrm{C}(\mathrm{M}: \mathrm{Mo}, \mathrm{Fe}, \mathrm{Cr})$ karbürlerinden ve matrise yayılmış ince taneli sekonder karbürlerden oluştuğu gözlenmiştir. Artan ferromolibden ve ferrovanadyum ilavesinin karbür tane boyutunu küçülttüğü tespit edilmiştir. Bununla birlikte hacimsel karbür oranı ve sertlik artış eğilimi sergilemiştir. En yüksek sertlik ve buna bağlı olarak en düşük hacimsel aşınma kaybı \%4 ferromolibden $+\% 10$ ferrovanadyum ilave edilen kaplamada tespit edilmiştir.

Anahtar Kelimeler: Kaplama, Sert dolgu, Seyrelme, Aşınma, Sertlik, Karbür

\section{The Effect of Molybdenum and Vanadium on Wear Resistance of Fe-Cr-C Hardfacing Alloys}

\begin{abstract}
Hardfacing coatings are one of the methods used in many engineering applications to increase the wear and corrosion resistance of workpieces. This study aims to examine the changes in microstructure and wear properties by adding carbide forming elements of molybdenum and vanadium together to $\mathrm{Fe}-\mathrm{Cr}-\mathrm{C}$ based hardfacing alloys. Each coating contains both vanadium and molybdenum. 3\%, 4\% ferromolybdenum, and $10 \%, 12 \%$ ferrovanadium were added to the $\mathrm{Fe}-\mathrm{Cr}-\mathrm{C}$ alloys. It was observed that the microstructure of coatings consists of primary $\mathrm{M}_{7} \mathrm{C}_{3}(\mathrm{M}: \mathrm{Fe}, \mathrm{Cr})$ and $\mathrm{M}_{2} \mathrm{C}(\mathrm{M}$ : $\mathrm{Mo}, \mathrm{Fe}, \mathrm{Cr})$ carbides and fine-grained secondary carbides dispersed in the matrix. It was observed that increasing ferromolybdenum and ferrovanadium addition reduces the carbide grain size. However, the volumetric carbide ratio and hardness showed an increasing trend with increasing ferrovanadium and ferromolybdenum. The highest hardness and consequently the lowest volumetric wear loss was determined in the coating including $4 \%$ ferromolybdenum $+10 \%$ ferrovanadium.
\end{abstract}

Keywords: Coating, Hardfacing, Dilution, Wear, Hardness, Carbide

"Sorumlu yazar (Corresponding author): Nilay ÇÖMEZ, nilay.comez@cbu.edu.tr 


\section{GIiRiş}

Bir bileşenin amaçlanan işlevini yerine getirmediğinde parçanın hasara uğradığı söylenir. Mühendislik bileşenlerinde hasar temel olarak dört farklı şekilde gözlenir: kırılma, korozyon, aşınma ve deformasyon. Aşınma, toplam hasarların \% 55 'ini oluşturur. Bu oran, aşınmanın azaltılmasına yönelik çalışmaların ne denli önemli olduğunu ortaya koymaktadır [1]. Yüzey kaplamaları, mühendislik uygulamalarında yer alan iş parçalarının ömrünü uzatmada oldukça etkili bir yaklaşımdır [2].

Sert dolgu, bir dolgu metalinin ana metal üzerine biriktirildiği yüzey kaplama türü olarak tanımlanır [3]. Sert dolgu kaplamalar, gaz tungsten ark kaynağ1 [4], gaz metal ark kaynağı, tozaltı ark kaynağı, özlü telle ark kaynağı, plazma ark kaynağ1 ve lazer kaynağı gibi yöntemlerle metalik yüzeylere uygulanabilmektedir [5]. Özellikle uygun maliyetli $\mathrm{Fe}-\mathrm{Cr}-\mathrm{C}$ sert dolgu kaplamaları, başta tarım, şeker üretimi ve madencilik gibi aşınmanın ön planda olduğu endüstriyel uygulamalarda aşınma ve korozyon direncini geliştiren bir yöntemdir [1,2]. Krom haricinde molibden, titanyum, tungsten, vanadyum ve niyobyum gibi karbür yapıcı elementler $\mathrm{Fe}-\mathrm{Cr}-\mathrm{C}$ alaşımlarına ilave edilerek yüksek sertlikte fazların çökelmesiyle ve matris fazının özelliklerinin optimize edilmesiyle aşınma direncine katkı sağlanmaktadır [1].

Qi ve arkadaşları, [6] sadece vanadyumu farklı oranlarda $\mathrm{Fe}-\mathrm{Cr}-\mathrm{C}$ alaşımına ilave ederek, vanadyum katkısının sert dolgu kaplamaların aşınma direncini artırdığını tespit etmişlerdir. Dilawary ve arkadaşları, [7] ise plazma transfer ark yöntemi ile 4140 çeliğinin yüzeyini sadece M2 yüksek hı çeliği ile ve molibdenle alaşımlandırılmış M2 yüksek hız çeliği ile kaplamışlardır. Çalışmaları sonucunda molibden ilavesi sertliği düşürse de aşınma direncini artırmıştır. Wang ve arkadaşları, [8] Fe-Cr-C sert dolgu alaşımına ferrotitanyum, ferrovanadyum ve ferromolibden ilave ederek oluşan $\mathrm{Fe}-\mathrm{Cr}-\mathrm{C}-\mathrm{Ti}-\mathrm{V}$ -
Mo alaşımından kaplamanın aşınma özelliklerini, ticari bir telle üretilen sert dolgu kaplaması ile kıyaslamalı olarak değerlendirmişlerdir. Lin ve arkadaşları, [9] vanadyum, molibden ve nikeli Fe$\mathrm{Cr}-\mathrm{C}$ alaşımına ayrı ayrı ekleyerek her bir alaşım elementinin kaplamanın mikroyapısına, sertliğine ve kırılma tokluğuna etkisini araştırmışlardır.

Literatürden edinilen bilgiler doğrultusunda, vanadyum ve molibdenin aynı anda ilave edildiği $\mathrm{Fe}-\mathrm{Cr}-\mathrm{C}$ sert dolgu alaşımları ile ilgili çalışmaların sınırlı sayıda olduğu kanısına varılmıştır. $\mathrm{Bu}$ çalışmanın amacı, molibden ve vanadyum ilavesiyle Fe-Cr-C-V-Mo sert dolgu kaplamaları oluşturmak ve farklı oranlarda gerçekleştirilen element ilavesinin sert dolgu alaşımlarının mikroyapısına, sertliğine ve aşınma direncine etkisini incelemektir.

\section{YÖNTEM}

\subsection{Sert Dolgu Kaplamaların Üretimi}

$\mathrm{Bu}$ çalışmada $5 \mathrm{~mm}$ kalınlığındaki St-37 çelik yüzeyine tek paso demir esaslı sert dolgu alaşımları kaplanmıştır (Şekil 1). Masif kaynak telinin ve ferro alaşımların kimyasal kompozisyonu Çizelge 1'de verilmiştir. Karbür yapıc1 element olarak krom, vanadyum ve molibden elementlerinin ferro alaşımlarından oluşan tozlar Çizelge 2'de verilen oranlarda karıştırılarak kaynak esnasında ergiyen masif tele takviye edilmiştir. Masif telin oluşturduğu arkın kaynak bölgesinde meydana getirdiği sıcaklık artışı ile debisi ayarlanabilen bir sistemle kaynak bölgesine takviye edilen toz karışımları ergitilerek kaplama alaşımlandırılmıştır. Kaplamayı oluşturan masif tel ve toz karışımının oranı sırasıyla \%70 ve $\% 30$ olarak ayarlanmıştır. Kaplamalar korumasız metal ark kaynağı ile üretilmiştir (Çizelge 3). Herhangi bir koruyucu gaz kullanılmamıştır ve kaplama uygulamasindan önce altlık malzemeye ön 1sıtma uygulanmamıştır. Kaplamalar kaynak sonrası hava ortamında soğumaya bırakılmıştır. 
Çizelge 1. Masif kaynak telinin ve ferro alaşımların kimyasal içeriği (ağ. \%)

\begin{tabular}{|c|c|c|c|c|}
\hline Element & Masif tel & FeV & FeMo & FeCr \\
\hline $\mathrm{V}$ & - & 57,5 & - & - \\
\hline $\mathrm{C}$ & 0,08 & 0,1 & 0,047 & 7,27 \\
\hline $\mathrm{Si}$ & 0,8 & 1,5 & - & 0,516 \\
\hline $\mathrm{S}$ & - & 0,017 & 0,043 & 0,061 \\
\hline $\mathrm{Mo}$ & - & - & 69,5 & - \\
\hline $\mathrm{P}$ & - & - & - & 0,01 \\
\hline $\mathrm{Cr}$ & - & - & - & 67,84 \\
\hline $\mathrm{Mn}$ & 1,45 & - & - & - \\
\hline $\mathrm{Fe}$ & \multicolumn{5}{|c|}{ Kalan } \\
\hline
\end{tabular}

Çizelge 2. Toz karışımları (ağ. \%)

\begin{tabular}{|c|c|c|c|}
\hline Kaplama & FeCr & FeV & FeMo \\
\hline 3FeMo-10FeV & 87 & 10 & 3 \\
\hline 3FeMo-12FeV & 85 & 12 & 3 \\
\hline 4FeMo-10FeV & 86 & 10 & 4 \\
\hline 4FeMo-12FeV & 84 & 12 & 4 \\
\hline
\end{tabular}

Çizelge 3. Kaynak parametreleri

\begin{tabular}{|l|c|}
\hline Gerilim (V) & $28-30$ \\
\hline Akım (A) & 350 \\
\hline Kaynak ilerleme hızı (mm/dak) & 140 \\
\hline Osilasyon genişliği (mm) & 40 \\
\hline Tel sürme hızı (mm/dak) & 170 \\
\hline Toz debisi (g/dak) & 145 \\
\hline Serbest tel boyu (mm) & $20-25$ \\
\hline
\end{tabular}

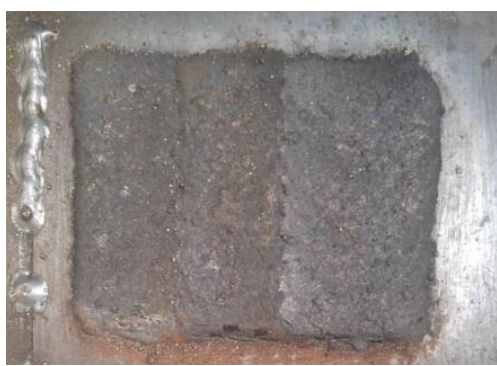

Şekil 1. 3FeMo-12FeV kaplamasının makro görüntüsü

\subsection{Metalografik Hazırlık}

Kaplamaların mikroyapı incelemeleri için yapılan metalografik hazırlık işlemleri sırasıyla: kesme, bakalite alma, zımparalama-parlatma ve dağlama şeklindedir. Uygun boyutlarda kesilen mikroyap1 numunelerinin yüzeyleri zımparalama ve parlatma işlemi ile optik mikroskop ve taramalı elektron mikroskobu (SEM) incelemelerine uygun hale getirilmiştir. SEM incelemeleri için dağlama işlemi uygulanmamıştır. Bununla birlikte optik mikroskop incelemelerinde fazlar arasındaki kontrastı oluşturabilmek için Kalling's çözeltisi ile dağlama gerçekleştirilmiştir. Kalling's çözeltisi, "33 $\mathrm{ml} \mathrm{H}_{2} \mathrm{O}, 1,5$ gram $\mathrm{CuCl}_{2}, 33 \mathrm{ml}$ metil alkol ve $33 \mathrm{ml} \mathrm{HCl}$ " kullanılarak hazırlanmıştır. Optik mikroskopta altlık malzemesi-kaplama ara yüzeyinde seyrelmenin mikroyapıya etkisi ve kaplamanın genelinde de karbür morfolojisi incelenmiştir. Ayrıca hacimsel karbür oranı Clemex yazılımıyla tespit edilmiştir (Şekil 2). Kaplamaların hacimsel karbür oranı, Şekil 2'de stereo mikroskop görüntüsü verilen $4 \mathrm{FeMo}-12 \mathrm{FeV}$ kaplaması üzerinde işaret edildiği gibi üst yüzeye yakın bölgelerde hesaplanmıştır. SEM-EDX (Enerji Yayılımlı X-Işını) analizi ile kaplamalarda oluşan fazların kimyasal içeriği belirlenmiştir. Ayrıca, Fe-Cr-C-Mo-V alaşımında oluşan karbür türlerinin tespit edilmesi için $30-90^{\circ}$ aralığında XRD taraması gerçekleştirilmiştir.
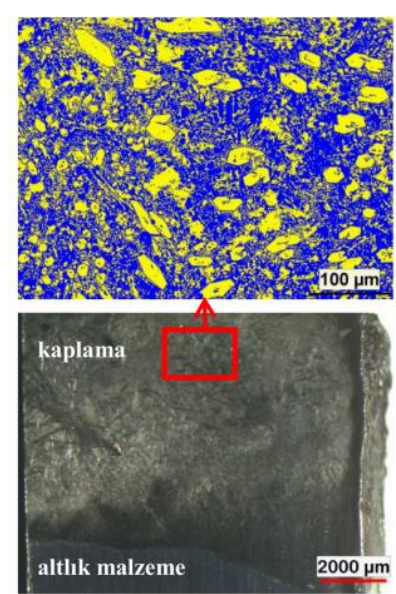

Şekil 2. $4 \mathrm{FeMo}-12 \mathrm{FeV}$ numunesinin faz analizi (sar1: karbür, mavi: matris)

\subsection{Sertlik Testi ve Aşınma Testi}

Kaplamalara Vickers uç kullanılarak EMCO Test DuraVision marka cihazda makro sertlik testi uygulanmıştır. Makro sertlik testinde HV10 metodunda göre 98,07 $\mathrm{N}$ ana yük 10 saniye boyunca uygulanmıştır. Sertlik ölçümü kaplamanın üst yüzeyinde yapılmıştır ve her kaplama numunesinden 3 ölçüm alınarak ortalama sertlik değeri hesaplanmıştır.

Kaplamaların aşınma testi "ball-on-disc" metoduna 
göre aşınma koşulu sağlayan CSM Tribometer cihazında gerçekleştirilmiştir (Şekil 3). Karşı eleman olarak $6 \mathrm{~mm}$ çapında alümina bilya tercih edilmiştir. Aşınma test parametreleri Çizelge 4'te verilmiştir. Aşınma sonrası Mitutoyo pürüzlülük ölçüm cihazı ile aşınma izinin profili elde edilmiştir. Profilometre cihazından dijital olarak elde edilen veriler Origin Pro yazılımına aktarılarak aşınma profilinin kesit alanı belirlenmiştir ve hacimsel aşınma kaybı hesaplanmıştır.

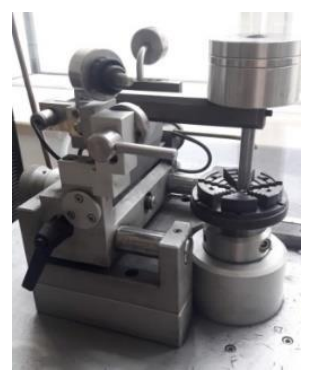

Şekil 3. CSM Tribometer aşınma cihazı

Çizelge 4. Aşınma test parametreleri

\begin{tabular}{|l|c|}
\hline Aşınma yarıçap1 & $4 \mathrm{~mm}$ \\
\hline Aşınma hızı & $10 \mathrm{~cm} / \mathrm{s}$ \\
\hline Yük & $10 \mathrm{~N}$ \\
\hline Aşınma mesafesi & 1500 \\
\hline
\end{tabular}

\section{ARAŞTIRMA BULGULARI}

\subsection{Mikroyapı}

Molibden ve vanadyum içeren Fe-Cr-C sert dolgu alaşımlarının mikroyapıları Şekil 4'te verilmiştir. Tüm kaplamalarda altıgen kesite sahip çubuksu primer karbürlerin oluştuğu gözlenmiştir. Yapılan SEM-EDX (Şekil 5) ve XRD (Şekil 6) analizleriyle bu karbürlerin $\mathrm{M}_{7} \mathrm{C}_{3} \quad(\mathrm{M}: \mathrm{Fe}, \mathrm{Cr})$ türüne ait olduğu belirlenmiştir. Kaplamalarda az miktarda $\mathrm{M}_{23} \mathrm{C}_{6}$ karbürünün oluşumu da XRD analizleriyle tespit edilmiştir. Ayrıca ince çökeltiler halinde ikincil karbürlerin matris fazına yayıldığı görülmüştür. Şekil 7'de altlık malzemesi ve kaplama malzemesinin ara yüzeyine ait mikroyapı görüntüleri verilmiştir. Altlık malzemesinin oda sıcaklığında olması sebebiyle, ergiyik kaplama malzemesi ve altlik malzeme arasında yüksek bir sıcaklık gradyanı meydana gelmektedir. Sıcaklık gradyanının yüksek olması, katılaşan kaplama malzemesinin düzlemsel büyüme sergilemesine sebep olmuştur. Deng ve arkadaşları, [10] seyrelme bölgesinde, yüksek sıcaklık gradyanı ve katı-ergiyik arayüzü boyunca gerçekleşen küçük yapısal aşırı soğumanın bir sonucu olarak arayüzün yakınında düzlemsel bir büyüme paterni gözlemlenebileceğini bildirmişlerdir. Ayrıca, 4FeMo- $10 \mathrm{FeV}$ ve $4 \mathrm{FeMo}-$ $12 \mathrm{FeV}$ kaplamalarının ara yüzeyinde yüksek soğuma hızına bağlı olarak martenzit oluşumu gözlenmiştir. Her iki kaplama da düzlemsel büyüme bölgesinden sonra dendritik katılaşmaya devam etmiştir.
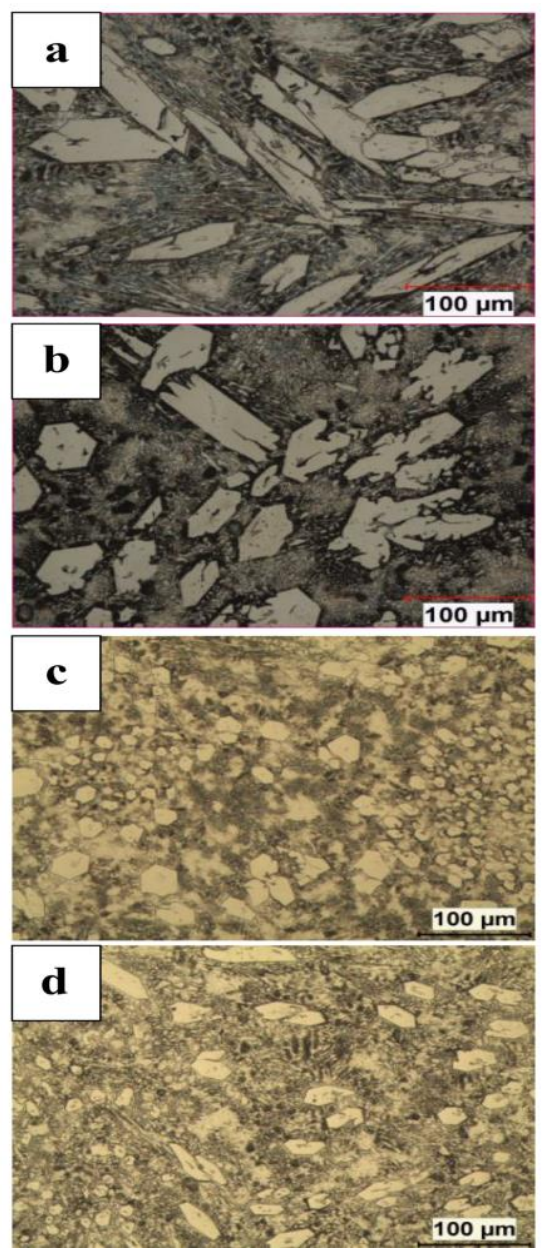

Şekil 4. Kaplamaların üst yüzeyine ait optik mikroskop görüntüleri: a) $3 \mathrm{FeMo}-10 \mathrm{FeV}$, b) $3 \mathrm{FeMo}-12 \mathrm{FeV}$, c) $4 \mathrm{FeMo}-10 \mathrm{FeV}$, d) $4 \mathrm{FeMo}-12 \mathrm{FeV}$ 


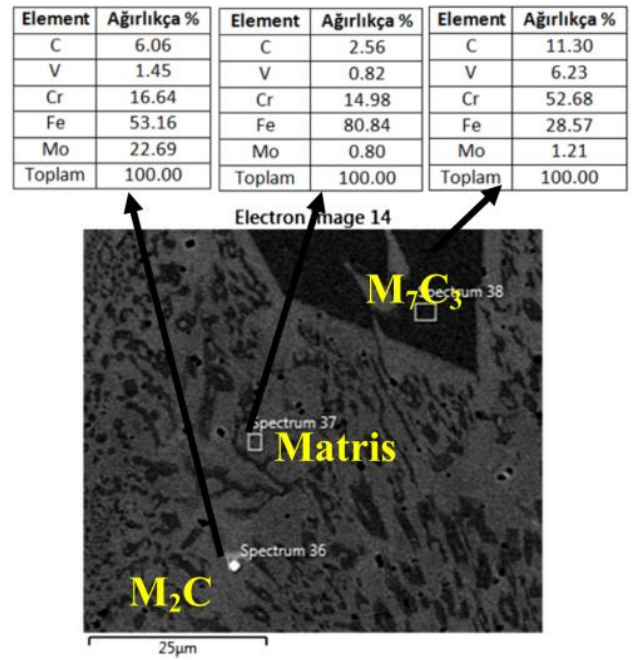

Şekil 5. 4FeMo-10FeV kaplamasının SEM-EDX analizi

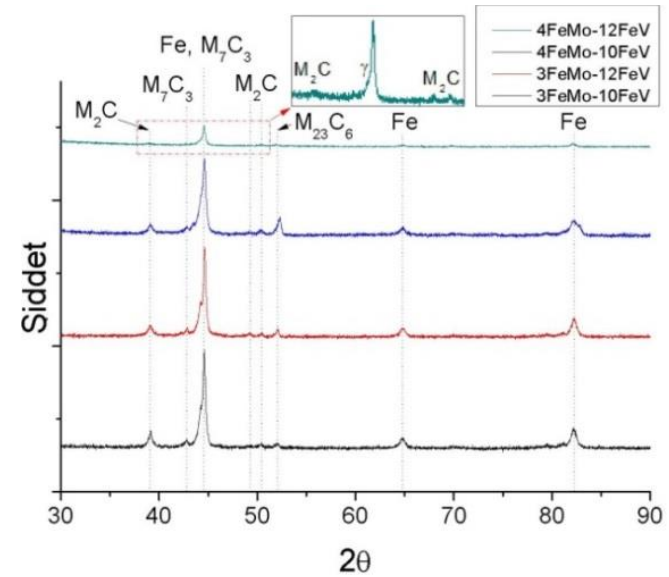

Şekil 6. Kaplamaların XRD analizi

Sert dolgu kaplamalarda sıklıkla karşılaşılan durumlardan biri seyrelmedir. Kaplama ve altlik arasında iyi bir metalurjik bağın elde edilmesi için minimum seyrelme gereklidir. Aşırı seyrelme, optimize edilmiş kimyasal bileşimin ve kaplamanın homojen özelliklerinin korunmasını olumsuz olarak etkiler. Seyrelme, kaplamadaki alaşım elementlerinin altlık malzemesine doğru difüzyonuna ve kaplamada biriken ergimiş altlık malzemesinin miktarında bağlıdır [11]. Başka bir ifade ile seyrelme, altlık malzemede meydana gelen ergime alanının toplam ergimiş alana oranı olarak tanımlanır [12].
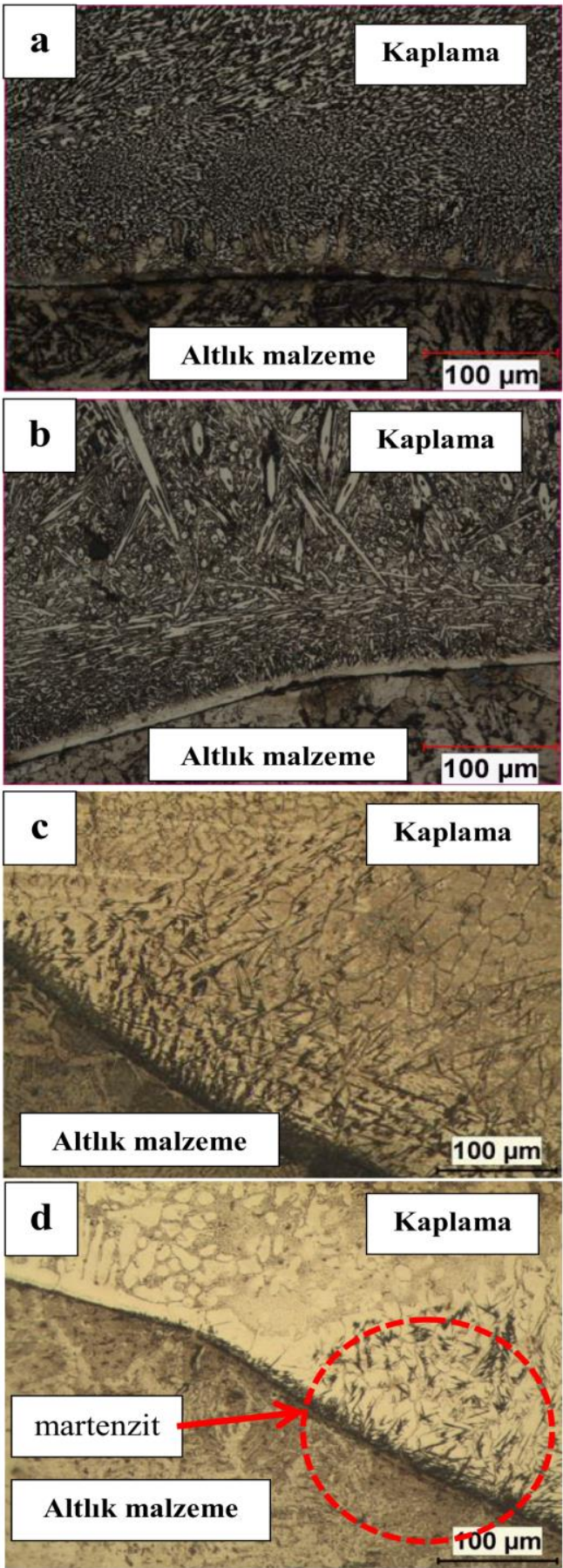

Şekil 7. Kaplama/altlık malzeme ara yüzeyi: a) $3 \mathrm{FeMo}-10 \mathrm{FeV}$, b) $3 \mathrm{FeMo}-12 \mathrm{FeV}$, c) $4 \mathrm{FeMo}-10 \mathrm{FeV}$, d) $4 \mathrm{FeMo}-12 \mathrm{FeV}$ 
Kaplamaların üretiminde ferrokrom tozu hem krom hem de karbon kaynağı olarak kullanılmıştır. Dolayısıyla toz karışımı içerisinde ferrovanadyum ve/veya ferromolibden oranının artması (Çizelge 1) karbon içeriğini düşürerek seyrelmenin 4FeMo-10FeV ve 4FeMo-12FeV kaplamalarında belirgin bir şekilde gözlenmesine sebep olmuştur. $\mathrm{Bu}$ kaplamaların altlık malzemeye yakın bölgelerinde primer karbür oluşumu meydana gelmemiştir (Şekil 7c ve 7d). Buna karşın 3FeMo$10 \mathrm{FeV}$ ve $3 \mathrm{FeMo}-12 \mathrm{FeV}$ kaplamaları ile altlik malzemesi arayüzeyinde, boyutları kaplamanın üst yüzeyindeki primer karbürlere kıyasla daha küçük olsa bile primer $\mathrm{M}_{7} \mathrm{C}_{3}$ karbür oluşumuna rastlanmıştır.

Optik mikroskop incelemelerinde molibden karbür tespit edilememiştir. Bununla birlikte XRD analizinde $\mathrm{M}_{2} \mathrm{C}(\mathrm{M}$ : $\mathrm{Mo}, \mathrm{Fe}, \mathrm{Cr})$ fazına ait piklere rastlanmıştır (Şekil 6). SEM incelemeleri sonucunda, altıgen şekilli primer $\mathrm{M}_{7} \mathrm{C}_{3}$ karbürleri haricinde düzensiz morfolojiye sahip ve molibden içeriği yaklaşık \%23 olan fazlar tespit edilmiştir (Şekil 5 ve Şekil 8). Bu fazların $\mathrm{M}_{2} \mathrm{C}$ karbürü (M: Mo, Fe, Cr) olduğu düşünülmektedir. Liu ve arkadaşları, [13] molibden ilavesinin katılaşma esnasinda $\mathrm{M}_{2} \mathrm{C}$ ve/veya $\mathrm{MC}$ karbürlerin oluşumuyla sonuçlandığını ve molibden karbürlerin daha küçük boyutta ve $\mathrm{M}_{7} \mathrm{C}_{3}$ karbürlerine göre daha düşük hacimsel oranda olduğunu belirtmişlerdir. SEM-EDX ve XRD analizleri sonucunda vanadyum karbür oluşumuna rastlanmamıştır. Vanadyumun $\mathrm{M}_{7} \mathrm{C}_{3}$ karbürleri içerisinde yer alma eğilimi sergilediği ve eser miktarda da matris fazında yer aldığı tespit edilmiştir (Şekil 5, Şekil 9).

\subsection{Sertlik ve Așınma Testi}

Sert dolgu kaplamaların hacimsel karbür oran1hacimsel aşınma kaybı-makro sertlik değerleri arasındaki ilişki Şekil 10'da verilmiştir. Molibden ve vanadyum içeriğindeki artışın hacimsel karbür oranını artırarak kaplama sertliğinin artmasına ve dolayısıyla aşınma miktarının azalmasına katkı sağladığı tespit edilmiştir. En yüksek sertlik ve aşınma direnci, maksimum vanadyum ve molibden içeriğine sahip olması nedeniyle $4 \mathrm{FeMo}-12 \mathrm{FeV}$ kaplamasinda beklenirken $4 \mathrm{FeMo}-10 \mathrm{FeV}$ kaplamasında elde edilmiştir. Toz karışımının içerisinde ferrovanadyum miktarının artmasına ve ferrokrom içeriğinin azalmasına bağlı olarak karbon miktarı düşmektedir. Sabet ve arkadaşları, [14] artan karbon ve karbür yapıcı element içeriğinin hacimsel karbür oranını artırarak sertliği artırdığını ifade etmişlerdir. Her ne kadar vanadyum, molibden, krom gibi karbür yapıc1 elementler ilave edilse de karbon miktarının azalması karbür oluşumunu azaltmıştır (Şekil 10). Ayrıca, XRD analizlerinden görüleceği gibi $\mathrm{M}_{23} \mathrm{C}_{6}$ karbürünün pik şiddeti en yüksek $4 \mathrm{FeMo}-10 \mathrm{FeV}$ numunesinde tespit edilmiştir (Şekil 6). $\mathrm{M}_{23} \mathrm{C}_{6}$ karbürü $\mathrm{M}_{7} \mathrm{C}_{3}$ karbürüne kıyasla daha düşük sertliktedir [15]. Artan $\mathrm{M}_{23} \mathrm{C}_{6}$ karbür miktarının 4FeMo-10FeV kaplamasının kırılma tokluğunu ve sertliğini dengeleyerek aşınma direncine olumlu katkıda bulunduğu düşünülmektedir.

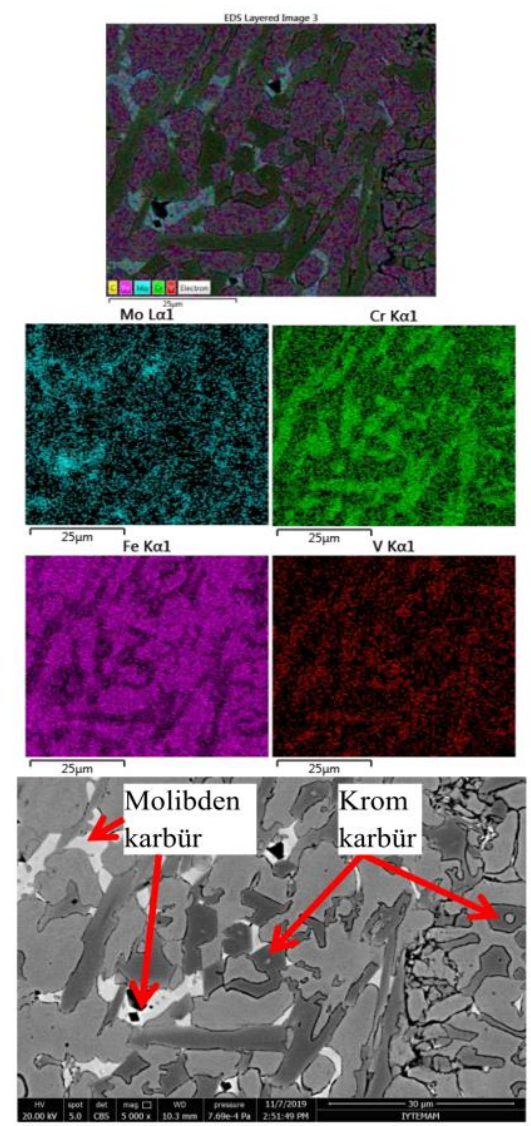

Şekil 8. $3 \mathrm{FeMo}-12 \mathrm{FeV}$ numunesinin elementel dağılım haritası 
Ferrovanadyum oranları sabit kalmak kaydıyla ferromolibden içeriği değișen kaplamalar kıyaslandığında -örneğin; $3 \mathrm{FeMo}-10 \mathrm{FeV}$ ve 4FeMo-10FeV- artan molibdenin hem sertliği hem de aşınma direncini artırdığı gözlenmiştir. Wang ve arkadaşlarının [16] belirttiği gibi molibden, hem katı çözelti sertleşmesi sağlayan hem de MC ya da $\mathrm{M}_{2} \mathrm{C}$ karbürleri şeklinde çökelerek dayanımı artıran element olarak görev almaktadır. $\mathrm{M}_{7} \mathrm{C}_{3}$ karbürlerin yanı sıra $\mathrm{M}_{2} \mathrm{C}$ karbür oluşumunu desteklemesi (Şekil 4 ve Şekil 6) ve matris fazında katı çözelti oluşturarak sertliği artırması sebebiyle molibden miktarındaki artış kaplamanın aşınma direncini artırmıştır.

Literatürde pek çok çalışmada [17-20] primer $\mathrm{M}_{7} \mathrm{C}_{3}$ karbürlerin aşınma direncini artırdı $\breve{g ̆}_{1}$ ifade edilmektedir. Bununla birlikte çalışma esnasında ağır yüke maruz kalmaları iri ve kırılgan primer karbürlerin matris fazından kırılarak dökülmelerine sebep olabilir ve aşınma şiddetini artırabilir [21]. Şekil 11'de görüldüğü gibi $3 \mathrm{FeMo}-10 \mathrm{FeV}$ kaplamasında oluşan iri primer karbürler (Şekil 4a) aşınma testi esnasında gevrek kırılmaya uğramıştır. $\mathrm{Bu}$ nedenle, iyi düzeyde bir aşınma direnci için iri boyutlu primer $\mathrm{M}_{7} \mathrm{C}_{3}$ karbürlerin oluşumu tek başına yeterli değildir. Venkatesh ve arkadaşları, [22] sert dolgu alaşımlarının aşınma direncinin karbür morfolojisine, dağılımına, oranına ve matrisin tokluğuna bağlı olduğunu ileri sürmüşlerdir. $\mathrm{Bu}$ çalışmada, artan molibden ve vanadyum miktarıyla daha ince taneli fakat yüksek hacimsel orana sahip $\mathrm{M}_{7} \mathrm{C}_{3}$ karbürlerin oluşumu hacimsel aşınma kaybını azaltmıştır.
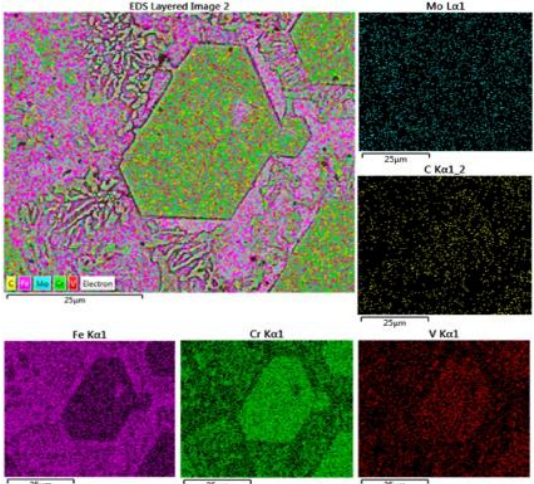

Şekil 9. 3FeMo-10FeV kaplamasına ait SEMEDX analizi

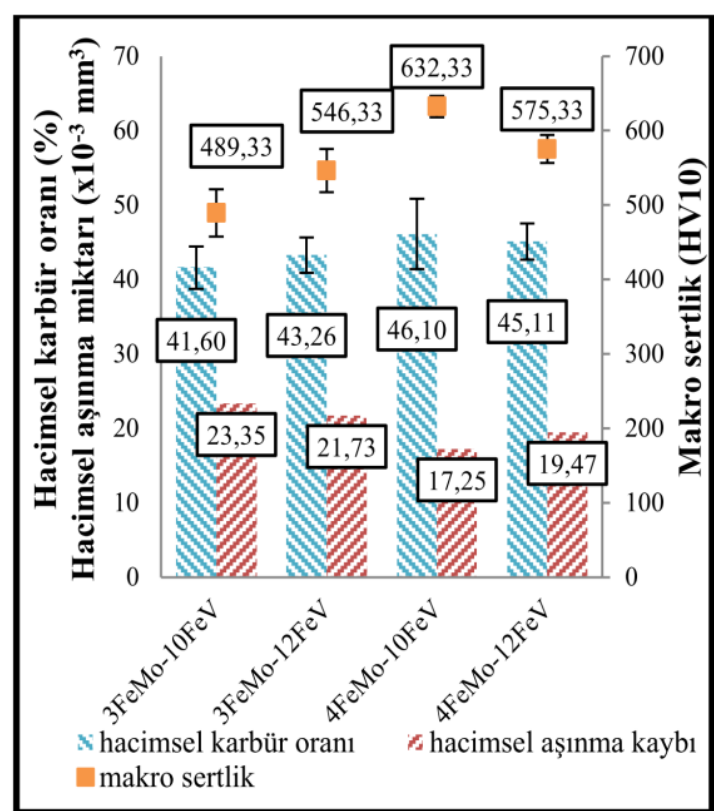

Şekil 10. Hacimsel karbür oranı-aşınma kayb1makro sertlik ilişkisi

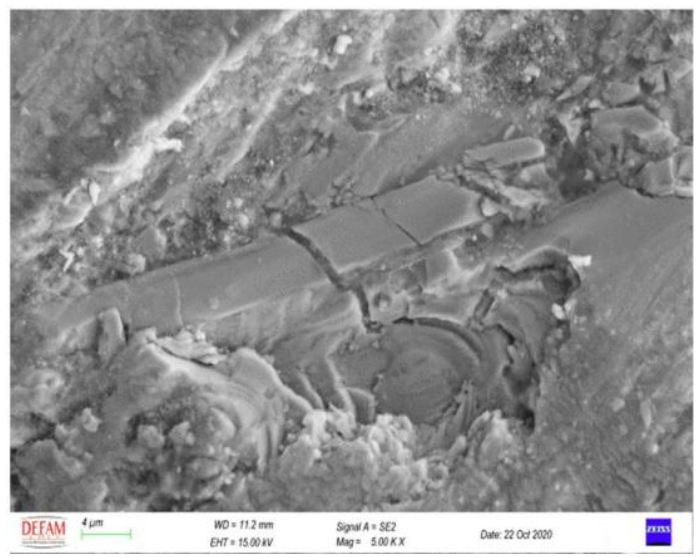

Şekil 11.3FeMo-10FeV kaplamasında karbürlerin gevrek kırılması

Așınma yüzeyleri incelendiğinde, abrazif aşınma oluşumunu işaret eden sürekli çiziklerin meydana geldiği görülmüştür (Şekil 12). Ayrıca bazı bölgelerde primer karbürlerde meydana gelen gevrek kırılmalara bağlı malzeme kaybının oluşturduğu çukurcuklara rastlanmıştır. 3FeMo$10 \mathrm{FeV}$ kaplamasının aşınma yüzeyinde hızlı soğumadan ileri geldiği düşünülen makro çatlak oluşumu tespit edilmiştir. 

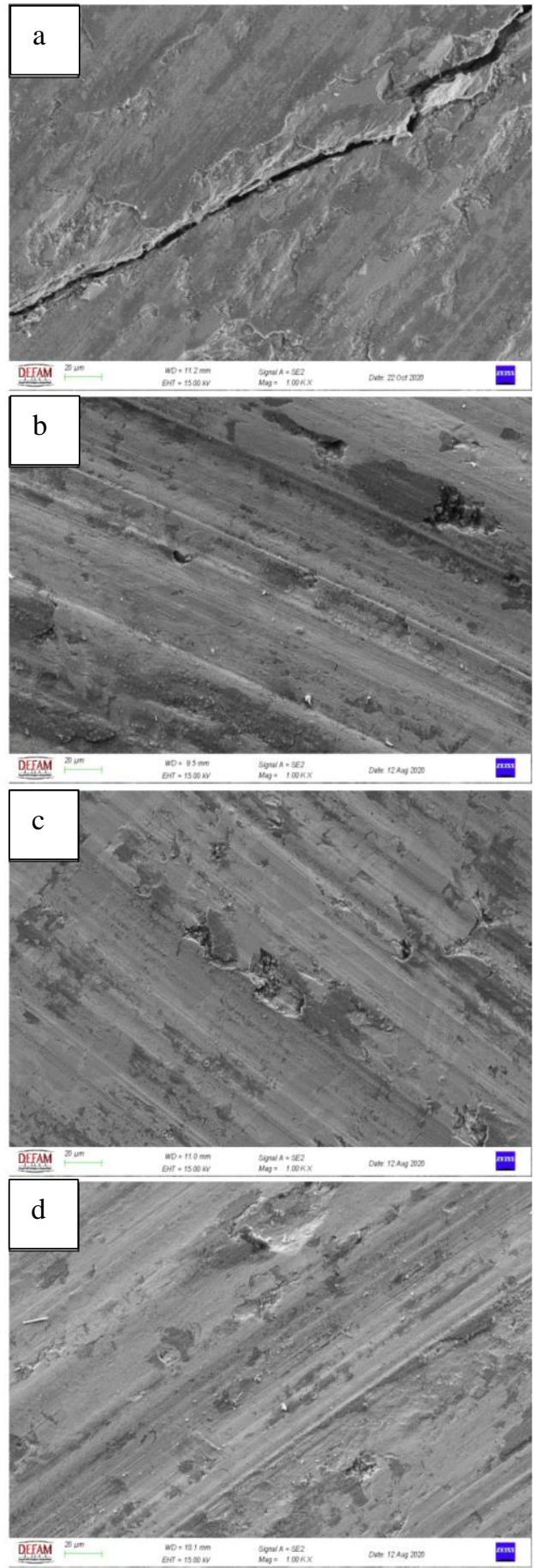

Şekil 12. Kaplamaların aşınma yüzeyi: a) $3 \mathrm{FeMo}-$ $10 \mathrm{FeV}$, b) $3 \mathrm{FeMo}-12 \mathrm{FeV}$, c) $4 \mathrm{FeMo}-$ $10 \mathrm{FeV}$, d) $4 \mathrm{FeMo}-12 \mathrm{FeV}$

\section{SONUÇLAR}

Çalışma kapsamında üretilen Fe-Cr-C-V-Mo sert dolgu kaplamalarına yapılan mikroyapı incelemelerinin, XRD analizi, sertlik ve aşınma testlerinin sonuçları kaplamaların içerdikleri ferromolibden ve ferrovanadyum oranlarına göre değerlendirilmiştir. Elde edilen bulgular aşağıda maddeler halinde özetlenmiştir:

1. Kaplamalarda vanadyum karbür oluşumuna rastlanmazken $\mathrm{M}_{7} \mathrm{C}_{3} \quad(\mathrm{M}: \mathrm{Fe}, \mathrm{Cr})$ primer karbürlerin yanı sıra molibden içeren $\mathrm{M}_{2} \mathrm{C}$ (M: Mo, $\mathrm{Fe}, \mathrm{Cr}$ ) karbürü ve $\mathrm{M}_{23} \mathrm{C}_{6}$ karbürü oluşmuştur. Vanadyum, primer $\mathrm{M}_{7} \mathrm{C}_{3}$ karbürleri içerisinde yer almıştır.

2. Artan molibden ve vanadyum miktarı primer karbür tane boyutunu küçültmüştür, bununla birlikte hacimsel karbür oranını artırmıştır. Artan hacimsel karbür oranı sertliği artırarak kaplamanın aşınma direncini geliştirmiştir. Özellikle molibden ilavesi $\mathrm{M}_{2} \mathrm{C}$ karbürleri oluşturarak aşınma direncine büyük ölçüde katkı sağlamıştır. En yüksek sertlik ve aşınma direnci $\% 4$ ferromolibden+\% 10 ferrovanadyum içeren kaplamada elde edilmiştir.

3. İri taneli ve kırllgan primer $\mathrm{M}_{7} \mathrm{C}_{3}$ karbürlerin aşınma esnasında gevrek kırılmaya uğraması ve kaplamada hızlı soğumaya bağlı olarak makro çatlakların oluşması aşınma direncini düşürmüştür. $\quad \mathrm{M}_{23} \mathrm{C}_{6}$ karbürünün ise aşınma direncine olumlu etkisi olduğu tespit edilmiştir. Tüm kaplamalarda abrazif aşınma türünün hakim olduğu görülmüş̧ür ve abrazif aşınma sonucunda kaplamaların aşınma yüzeylerinde sürekli çizikler meydana gelmiştir.

\section{TEŞEKKÜR}

$\mathrm{Bu}$ çalışma, MCBÜ Bilimsel Araştırma Projeleri Koordinasyon Birimi tarafından "2019-074" numaralı proje ile desteklenmiştir. Yazarlar MCBÜ Bilimsel Araştırma Projeleri Koordinasyon Birimi'ne sağlanan destek dolayısıyla teşekkür eder. 


\section{KAYNAKLAR}

1. Pawar, S., Jha, A.K., Mukhopadhyay, G., 2019. Effect of Different Carbides on the Wear Resistance of Fe-based Hardfacing Alloys. Int. J. Refract. Met. H., 78, 288-295.

2. Nagentrau, M., Tobi, A.M., Sambu, M., Jamian, S., 2019. The Influence of Welding Condition on the Microstructure of WC Hardfacing Coating on Carbon Steel Substrate. Int. J. Refract. Met. H., 82, 43-57.

3. Balaguru, S., Abid, M., Gupta, M., 2020. Investigations on Different Hardfacing Processes for High Temperature Applications of Ni-Cr-B-Si Alloy Hardfaced on Austenitic Stainless Steel Components. Journal of Materials Research and Technology, 9(5), 10062-10072.

4. Balalan, Z., Mehmet, Y.A.Z., Y1lmaz, S.O., 2017. GTAW Yöntemi ile Oluşturulan FeBFeTi-FeW-C Kaplamalarının Mikroyapı ve Adhesiv Aşınma Davranışının İncelenmesi. Fırat Üniversitesi Mühendislik Bilimleri Dergisi, 29(2), 203-212.

5. Zahiri, R., Sundaramoorthy, R., Lysz, P., Subramanian, C., 2014. Hardfacing Using Ferro-alloy Powder Mixtures by Submerged Arc Welding. Surf. Coat. Tech., 260, 220-229.

6. Qi, X., Jia, Z., Yang, Q., Yang, Y., 2011. Effects of Vanadium Additive on Structure Property and Tribological Performance of High Chromium Cast Iron Hardfacing Metal. Surf. Coat. Tech., 205(23-24), 5510-5514.

7. Dilawary, S.A.A., Motallebzadeh, A., Houdková, Š., Medlin, R., Haviar, S., Lukáč, F., Afzal, M., Cimenoglu, H., 2018. Modification of M2 Hardfacing: Effect of Molybdenum Alloying and Laser Surface Melting on Microstructure and Wear Performance. Wear, 404, 111-121.

8. Wang, X., Han, F., Liu, X., Qu, S., Zou, Z., 2008. Microstructure and Wear Properties of the Fe-Ti-V-Mo-C Hardfacing Alloy. Wear, 265(5-6), 583-589.

9. Lin, C.M., Chang, C.M., Chen, J.H., Wu, W., 2010. The Effects of Additive Elements on the Microstructure Characteristics and Mechanical Properties of $\mathrm{Cr}-\mathrm{Fe}-\mathrm{C}$ Hard-Facing Alloys. J.
Alloy. Compd., 498(1), 30-36.

10. Deng, H., Shi, H., Tsuruoka, S., 2010. Influence of Coating Thickness and Temperature on Mechanical Properties of Steel Deposited with Co-based Alloy Hardfacing Coating. Surf. Coat. Tech., 204(23), 3927-3934.

11. Rovatti, L., Lemke, J.N., Lecis, N.O.R.A., Stejskal, O., Vedani, M., 2015. Effect of Dilution on Microstructure and Wear Resistance of a Fe-based Hardfacing Alloy with a High Amount of Carbide-forming Elements. Conference Papers in Science, 2015, Article ID 276374, Hindawi

12. Singh, M., Majid, M., Akhtar, M.A., Arora, H., Chawla, K., 2017. Wear Behaviour of SMAW Hardfaced Mild Steel and Influence of Dilution Upon Hardfacing Properties. International Journal of Mechanical Engineering and Technology, 8(7), 1652-1661.

13. Liu, D., Wang, J., Zhang, Y., Kannan, R., Long, W., Wu, M., Wang, Y., Li, L., 2019. Effect of Mo on Microstructure and Wear Resistance of Slag-free Self-shielded MetalCored Welding Overlay. J. Mater. Process. Tech., 270, 82-91.

14. Sabet, H., Khierandish, S., Mirdamadi, S., Goodarzi, M., 2011. The Microstructure and Abrasive Wear Resistance of $\mathrm{Fe}-\mathrm{Cr}-\mathrm{C}$ Hardfacing Alloys with the Composition of Hypoeutectic, Eutectic, and Hypereutectic at $\mathrm{Cr} / \mathrm{C}=6$. Tribol. Lett., 44(2), 237-245.

15. Higuera-Cobos, O.F., Dumitru, F.D., MesaGrajales, D.H., 2016. Improvement of Abrasive Wear Resistance of the High Chromium Cast Iron ASTM A-532 Through Thermal Treatment Cycles. Revista Facultad de Ingeniería, 25(41), 93-103.

16. Wang, X.H., Han, F., Liu, X.M., Qu, S.Y., Zou, Z.D., 2008. Effect of Molybdenum on the Microstructure and Wear resistance of Febased Hardfacing Coatings. Mat. Sci. Eng. AStruct., 489(1-2), 193-200.

17. Cruz-Crespo, A., Fernández-Fuentes, R., Ferraressi, A.V., Gonçalves, R.A., Scotti, A., 2016. Microstructure and Abrasion Resistance of Fe-Cr-C and Fe-Cr-C-Nb Hardfacing Alloys Deposited by S-FCAW and Cold Solid Wires. Soldagem \& Inspeção, 21(3), 342-353. 
18. Zhou, Y.F., Yang, Y.L., Li, D., Yang, J., Jiang, Y.W., Ren, X.J., Yang, Q.X., 2012. Effect of Titanium Content on Microstructure and Wear Resistance of Fe-Cr-C Hardfacing Layers. Weld. J., 91(8), 229-235.

19. Chotěborský, R., Hrabě, P., Müller, M., Savková, J., Jirka, M., 2008. Abrasive Wear of High Chromium Fe-Cr-C Hardfacing Alloys. Research in Agricultural Engineering, 54(4), 192-198.

20. İrizalp, S.G., Saklakoğlu, N., İldaş, G., Demirok, S., 2018. 1.2714 Çeliği Üzerine Sert Dolgu Kaynağı ile Kaplanmış Fe-Cr-V Esaslı Alaşımın Malzeme Özelliklerinin İncelenmesi. Çukurova Üniversitesi Mühendislik-Mimarlık Fakültesi Dergisi, 33(1), 35-46.

21. Królicka, A., Szczepański, Ł., Konat, Ł., Stawicki, T., Kostencki, P., 2020. The Influence of Microstructure on Abrasive Wear Micro-mechanisms of the Claddings Produced by Welding Used in Agricultural Soil. Materials, 13(8), 1920

22. Venkatesh, B., Sriker, K., Prabhakar, V.S.V., 2015. Wear Characteristics of Hardfacing Alloys: State-of-the-art. Procedia Materials Science, 10, 527-532. 